\title{
De buena madera. Análisis antracológico de restos leñosos carbonizados procedentes del sitio Los Tres Ombúes (partido de Punta Indio, provincia de Buenos Aires)
}

\author{
Naiquen Ghiani Echenique, Celeste Valencia y María Clara Paleo \\ Recibido 17 de julio 2019. Aceptado 30 de diciembre 2019
}

\begin{abstract}
RESUMEN
El sitio arqueológico Los Tres Ombúes (partido de Punta Indio, provincia de Buenos Aires) corresponde a grupos cazadores-recolectores del Holoceno tardío y fue datado en $1110 \pm 19$ AP. Este trabajo aborda su conjunto antracológico, conformado por 100 carbones, con el fin de contribuir al conocimiento de los grupos que habitaron dicho sitio, y en particular, de sus prácticas de obtención y empleo de leña. Para la caracterización de los restos leñosos carbonizados se constituyó una colección de referencia experimental de las especies arbóreas próximas al sitio. El conjunto arqueológico fue analizado mediante observaciones microscópicas y su comparación con dicha colección. Se determinó taxonómicamente el 78\% del conjunto, con representación de las especies arbóreas Celtis tala, Jodina rhombifolia, Schinus longifolius, Scutia buxifolia, Erythrina crista-galli y Salix humboldtiana. Los resultados indican la presencia y el uso de estas especies en el pasado y permiten indagar en torno a las prácticas de obtención y empleo de leña.
\end{abstract}

Palabras clave: Cazadores-recolectores; Leña; Análisis antracológico; Punta Indio.

\begin{abstract}
MADE FROM GOOD WOOD: ANTHRACOLOGICAL ANALYSIS OF CARBONIZED WOOD REMAINS FROM LOS TRES OMBUES SITE, PUNTA INDIO MUNICIPALITY, BUENOS AIRES PROVINCE. LOS Tres Ombúes archaeological site corresponds to Late Holocene hunter-gatherers and has been dated to $1110 \pm 19$ BP. This article presents the anthracological evidence, consisting of 100 charcoal samples, in order to contribute to the knowledge of the human groups which inhabited the site, especially their practices of obtaining and using firewood. A reference collection was created to identify the charcoals using the tree species in the vicinity of the site. The samples were analyzed by microscopic observation and comparison with the reference collection. Seventy-eight percent of the samples were taxonomically determined, including Celtis tala, Jodina rhombifolia, Schinus longifolius, Scutia buxifolia, Erythrina cristagalli and Salix humboldtiana. These results suggest the presence of these species in the past and their use in the practices of obtaining and using firewood.
\end{abstract}

Keywords: Hunter-gatherers; Wood; Anthracological analysis; Punta Indio.

\footnotetext{
Naiquen Ghiani Echenique. Laboratorio de Análisis Cerámico, Facultad de Ciencias Naturales y Museo, Universidad Nacional de La Plata (UNLP). Calle 64 N³ (1900), La Plata, Argentina. E-mail: naiqueng@gmail.com

Celeste Valencia. Laboratorio de Análisis Cerámico, Facultad de Ciencias Naturales y Museo, UNLP. Calle 64 N³ (1900), La Plata, Argentina. E-mail: cvalencia@fcnym.unlp.edu.ar

María Clara Paleo. Laboratorio de Análisis Cerámico, Facultad de Ciencias Naturales y Museo, UNLP. Calle 64 N³ (1900), La Plata, Argentina. E-mail: mcpaleo@fcnym.unlp.edu.ar
} 


\section{INTRODUCCIÓN}

Los recursos madereros son utilizados como combustible para cocinar alimentos, manufacturar artefactos, generar calor y/o luz, y como materia prima para la confección de artefactos de madera y construcciones, entre otras posibilidades. Su empleo implica acciones de aprovisionamiento, traslado, procesamiento y descarte de las especies vegetales. Así, la identificación taxonómica de los carbones arqueológicos permite inferir los recursos leñosos utilizados y evaluar las modalidades de obtención y empleo que llevaron adelante los grupos humanos, vinculados con las necesidades sociales, el conocimiento de sus propiedades, entre otros aspectos. Además, posibilita indagar la composición florística del entorno para el momento de ocupación (Piqué i Huerta, 1999, 2006; Solari, 2000).

Se presenta un análisis antracológico de los restos leñosos carbonizados que fueron recuperados en el sitio arqueológico Los Tres Ombúes, partido de Punta Indio (provincia de Buenos Aires) (Figura 1). Se trata de un sitio de cazadores-recolectores del Holoceno tardío, ubicado a $350 \mathrm{~m}$ del Río de la Plata y a $20 \mathrm{~m}$ del arroyo La Matilde, en un cordón conchil-arenoso sobre el cual se desarrolla una abundante vegetación de talar. Este bosque nativo característico del noreste bonaerense se vincula estrechamente con los bosques xerófitos chaqueños y presenta una asociación típica de especies, si bien su composición es variable a lo largo de su distribución (Parodi, 1940; Vervoorst, 1967).

Los sitios arqueológicos más cercanos a Los Tres Ombúes son Las Marías (Paleo y Pérez Meroni, 2007; Pérez Meroni et al., 2010) y la localidad arqueológica Barrio San Clemente (Sempé et al., 1991; Balesta et al., 1997; Paleo et al., 2002; Paleo y Pérez Meroni, 2004), ubicados hacia el noroeste, a 23 y $16 \mathrm{~km}$ respectivamente. El sector costero

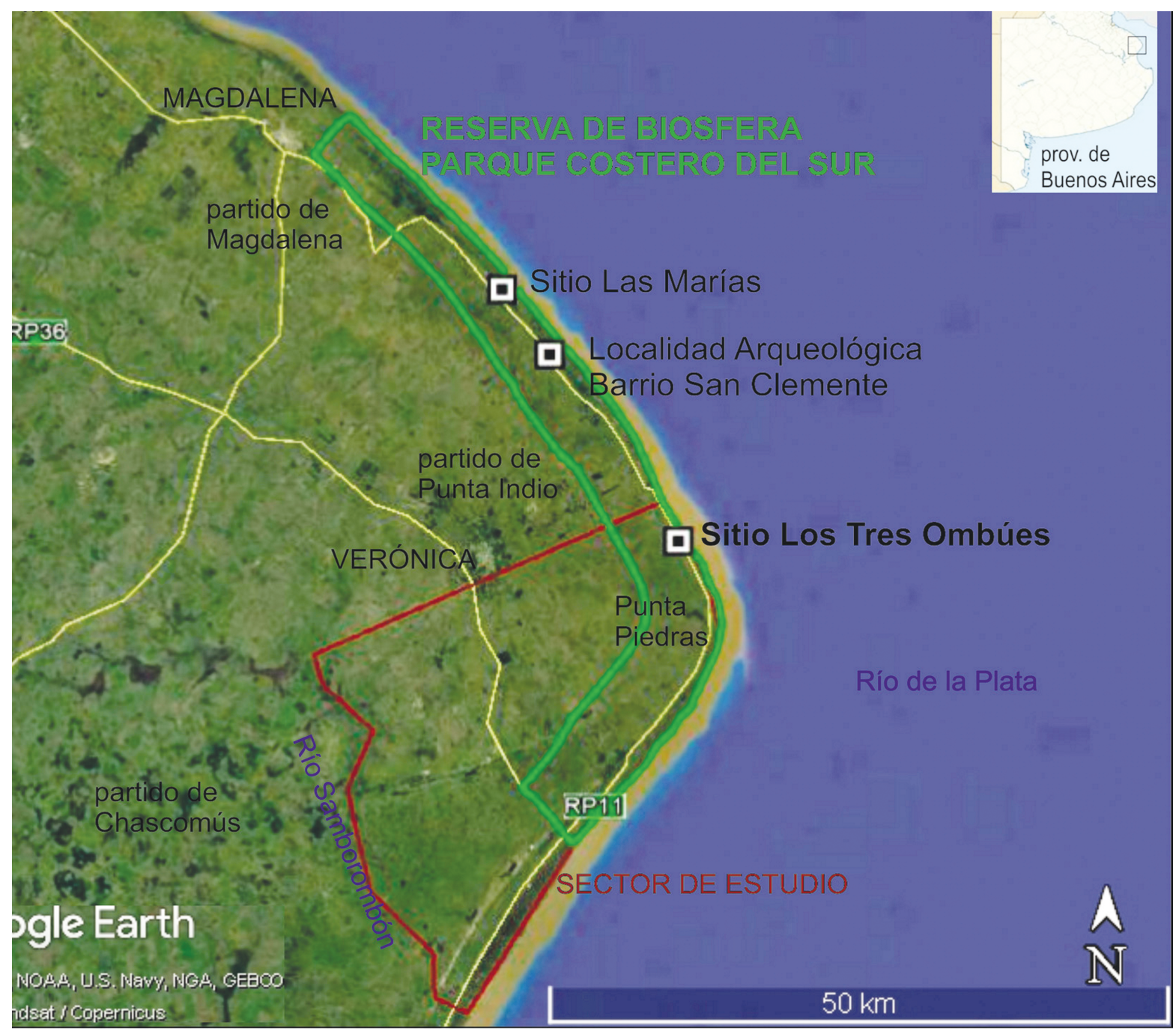

Figura 1. Sitio arqueológico Los Tres Ombúes. Ubicación geográfica dentro de la zona de estudio y en la Reserva de Biosfera Parque Costero del Sur. Además, se señalan el sitio arqueológico Las Marías y la Localidad Arqueológica Barrio San Clemente (Modificado de Google Earth Pro 2017). 
de los partidos de Magdalena y Punta Indio donde estos se encuentran conforma un área protegida, el Parque Costero del Sur (PCS), declarado Reserva de Biosfera por la UNESCO en 1984. El PCS comprende un valioso patrimonio natural-cultural. Concentra talares, pastizales y humedales vinculados con el Río de la Plata, con evidencias arqueológicas, estancias ganaderas y poblados, entre los que se destaca la localidad de Punta del Indio.

Los cordones elevados con talar fueron habitados por grupos cazadores-recolectores prehispánicos. Entre las prácticas sociales vinculadas con el proceso de habitar el paisaje, se encuentran las modalidades de obtención y empleo de leña para la realización de fogones. De tal modo, el objetivo de este trabajo es contribuir al conocimiento de los grupos cazadores-recolectores que habitaron el sitio Los Tres Ombúes durante el Holoceno tardío, y particularmente de las prácticas de obtención y empleo de leña, a partir de la caracterización de los restos carbonizados y su identificación taxonómica. La información producida a partir de este análisis se integra en un marco regional, en el cual se consideran otros sitios arqueológicos del noreste bonaerense que también se encuentran en el talar, tanto en el litoral rioplatense (e.g., Balesta et al., 1997; Brunazzo, 1999; Paleo et al., 2002; Paleo y Pérez Meroni, 2004, 2007), como en la cuenca inferior del río Salado y la bahía de Samborombón (e.g., Aldazábal et al., 2004; González, 2005; González y Frère, 2009; Aldazábal y Vázquez, 2015).

Para los sitios ubicados en la llanura costera de los partidos de Magdalena y Punta Indio, se reconoció que distintos agentes y procesos posdepositacionales tienden a la destrucción de macrorrestos vegetales (Pérez Meroni et al., 2010). Sin embargo, para el sitio El Ancla (redefinido como San Clemente I, II y III) fue referida una estructura de combustión no definida, la única mencionada para la localidad arqueológica Barrio San Clemente. Se realizó la datación radiocarbónica de un carbón vegetal procedente de aquella, de $220 \pm 60$ AP, mediante el método convencional (Sempé et al., 1991). Balesta et al. (1997) dudaron de la fecha tardía obtenida, ya que, por un lado, el registro recuperado no evidencia contacto hispano-indígena; por otro, una datación de restos humanos realizada posteriormente brindó un fechado de $1550 \pm 90$ AP. En el sitio Las Marías se identificaron dos estructuras de combustión, definidas como sectores de $1 \mathrm{~m}$ de diámetro aproximadamente, con una coloración gris oscura y mezcla de pequeños trozos de carbón frágil y quebradizo, fragmentos astillados de huesos con intensa alteración térmica y tiestos cerámicos, posiblemente utilizados como material refractario (Paleo y Pérez Meroni, 2007; Pérez Meroni et al., 2010). Para otras áreas del noreste bonaerense se reconocieron fragmentos pequeños de carbones, dispersos, algunos de los cuales fueron empleados para realizar dataciones radiocarbónicas, como en la localidad arqueológica La Guillerma del partido de Chascomús (González, 2005); y en otros casos, estructuras de combustión. Brunazzo (1999) consideró que estas son difícilmente identificables en el suelo oscuro y húmedo, y se definen por la presencia de pequeños carbones concentrados junto con restos óseos de intensa alteración térmica. También se identificaron estructuras de combustión en los sitios La Higuera, partido de Berisso (Brunazzo, 1997), y El Divisadero Monte 6, partido de General Lavalle (Aldazábal y Vázquez, 2015). En cuanto a las determinaciones taxonómicas, en La Higuera se identificaron restos pertenecientes a la familia Cyperaceae, así como también de Celtis tala y posiblemente Schinus sp. y Geoffroea sp. (Brunazzo, 1997). Además, en la localidad arqueológica La Guillerma se identificaron carbones de C. tala, Schinus sp. y Salix sp. (González y Frére, 2009), y también de C. tala en El Divisadero Monte 6 (Aldazábal y Vázquez, 2015).

\section{CARACTERIZACIÓN DEL SITIO LOS TRES OMBÚES}

\section{El paisaje}

Se considera que la perspectiva tradicional en arqueología, que aborda al entorno como fuente de recursos, puede superarse desde la conceptualización de un paisaje humanizado, activo en la conformación de las prácticas sociales, generado por las interacciones entre humanos y otros agentes a lo largo del tiempo. En este sentido, el paisaje actual puede entenderse como un documento que contiene información sobre el del pasado, dado que constituye un registro de las diversas prácticas que los grupos Ilevaron adelante al habitarlo (Orejas, 1991; Ingold, 1993). Es por ello que analizar las características del sitio y su lugar en el entorno, de forma complementaria con los materiales arqueológicos, posibilita una aproximación a los modos en que las personas significan, construyen y habitan el espacio (e.g., Acuto, 2013). 
El entorno del sitio y sus proximidades abarca tres microambientes dispuestos en sentido transversal a la costa, atravesados por el arroyo La Matilde, como describen Paleo et al. (2002) para la localidad arqueológica Barrio San Clemente. La desembocadura del arroyo conecta con la planicie costera del Río de la Plata, donde habitualmente se encuentran las especies arbóreas Erythrina crista-galli L. (ceibo) y Salix humboldtiana Willd. (sauce). En la actualidad su presencia es escasa, y responde en mayor medida a ejemplares plantados para combatir la erosión. Hacia el interior se encuentra la llanura costera, de $1 \mathrm{~km}$ de ancho en el sector de prospección, con dos cordones conchiles-arenosos sobre los que se desarrolla el talar, separados por un intercordón inundable con vegetación de pastizal húmedo. En el bosque predominan las especies arbóreas Celtis tala Gillies ex Planch. (tala), Schinus longifolius (Lindl.) Speg. (molle) y Scutia buxifolia Reissek (coronillo), y en menor proporción se encuentran Jodina rhombifolia (Hook. \& Arn.) Reissek. (sombra de toro) y Phytolacca dioica L. (ombú). El cordón próximo a la costa está atravesado por la RP № 11 . Otros rasgos de alteración antrópica, como la construcción de viviendas y las actividades agrícola-ganaderas, son visibles en ambos cordones. Por último, más allá del sector prospectado hacia el interior, la antigua Ilanura intermareal ocupa cerca de $2 \mathrm{~km}$, y constituye el límite interior de la llanura costera en su encuentro con la planicie pampeana, dominada por pastizales y ampliamente afectada por la producción agrícola-ganadera (Ghiani Echenique y Paleo, 2018).

En cuanto a la temporalidad de este paisaje dinámico, en forma posterior a los 3000 años AP habría comenzado la formación del suelo sobre el sustrato de la Ilanura costera. Desde entonces, se habría dado su relativa estabilización, indicada por la formación del bosque de tala hace unos 2000 años, según análisis polínicos que corroboran su asociación con la presencia humana en el área desde 1800 años AP (Paez et al., 1999). De este modo, durante la ocupación humana, el talar constituyó un recurso predecible y disponible, aunque ocurrieron variaciones menores. Hacia los 300-200 años AP se nota un incremento en los taxones hidrófilos que evidenciaría una mayor disponibilidad hídrica en canales e intercordones y la estabilización de la planicie costera (Paleo et al., 2002). Las diversas modificaciones del talar hasta la actualidad no responden únicamente a dichos factores, sino al proceso de interacción con los grupos humanos que lo habitaron. Por ejemplo, su explotación como fuente de leña fue intensa en el área hacia mediados del siglo XX. Aunque no fue ampliamente afectada la extensión del bosque, se modificaron las características de los árboles en vinculación al proceso de rebrote de cepa (Arturi y Goya, 2004). Su permanencia hasta la actualidad podría deberse al bajo interés por el desmonte en el marco de la actividad ganadera, pero en ocasiones se realiza la extracción de conchilla, que constituye una actividad económica altamente destructiva (Arturi, 2006).

\section{El sitio y su registro antracológico}

En Los Tres Ombúes se excavaron dos cuadrículas $\left(4,5 \mathrm{~m}^{2}\right)$ y se realizaron, además, 13 sondeos sistemáticos que permiten corroborar la distribución de material arqueológico en un área extensa, de aproximadamente $1300 \mathrm{~m}^{2}$ (Figura 2). Se trata de un sitio unicomponente que, a partir de los análisis efectuados, fue considerado un espacio habitacional de cazadores-recolectores, con evidencia de actividades múltiples. Una datación radiocarbónica lo ubica en $1110 \pm 19$ AP (hueso de Blastocerus dichotomus). Las características del registro arqueológico indicarían un amplio conocimiento de las modalidades tecnológicas y de obtención y procesamiento de recursos, como también la elección de lugares para habitar, en particular lomadas cubiertas de talar (Ghiani Echenique y Paleo, 2018).

A partir de las excavaciones se registró un suelo inmaduro, sin estructuras, de textura arenosa debido a su desarrollo sobre un sustrato conchil-arenoso con abundante arena, con un perfil compuesto por horizontes A-AC-C. El material arqueológico se encontró en el suelo actual, en los primeros dos horizontes, hasta $0,65 \mathrm{~m}$ de profundidad y con una mayor concentración entre los 0,25 y los 0,30 m. Se recuperaron 2963 elementos, entre fragmentos cerámicos, masas de arcilla, material arqueofaunístico y malacológico; lítico, vidrio, metal y material antracológico. Este último conjunto, conformado por 100 carbones pequeños, es objeto de este trabajo.

\section{MATERIALES Y MÉTODOS}

Durante la excavación de Los Tres Ombúes, el conjunto de restos leñosos carbonizados fue recuperado de forma manual y mediante el tamizado en seco con malla de $5 \mathrm{~mm}$. Los carbones se 


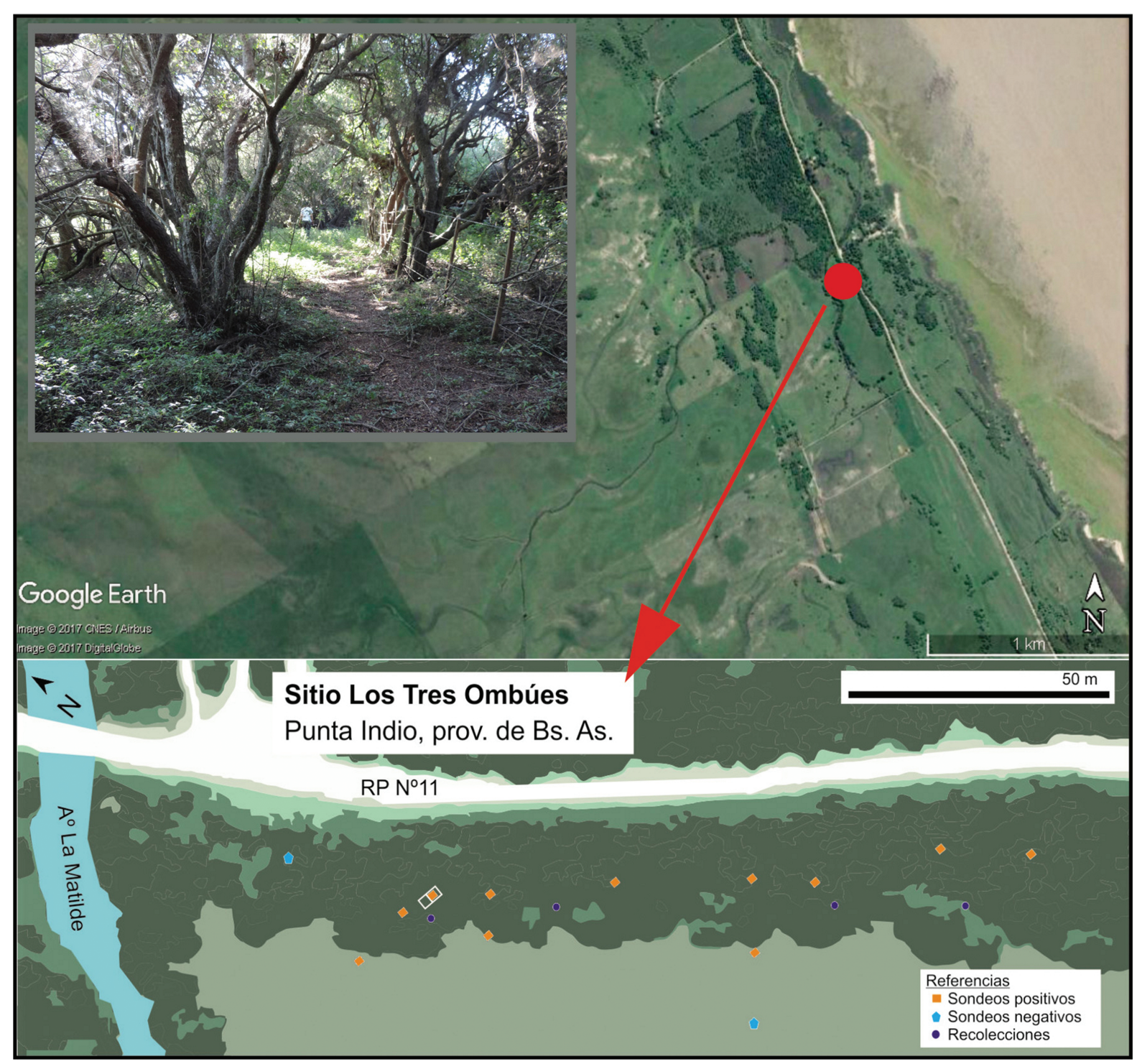

Figura 2. Sitio arqueológico Los Tres Ombúes. Sector de prospección denominado llanura costera rioplatense y arroyo La Matilde, donde se ubica el sitio Los Tres Ombúes, y planta del sitio con sondeos, recolecciones superficiales y las cuadrículas F2 y F3 (Modificado de Google Earth Pro 2017). En detalle, entorno del sitio dominado por el talar.

encontraban dispersos en la secuencia estratigráfica, hasta $0,55 \mathrm{~m}$ de profundidad. Según autores como Piqué i Huerta (1999) y Solari (2000), los carbones dispersos proceden de múltiples fogones y combustiones ocurridas durante la ocupación de un sitio, que habrían sido fragmentados y diseminados en el sedimento mediante la acción de agentes naturales y antrópicos (viento, pisoteo, limpieza de fogones, etc.) Por dicho motivo, estos carbones representan mejor que los concentrados la utilización de los recursos leñosos en el sitio. Cabe destacar que en Los Tres Ombúes no se reconocieron estructuras de combustión, lo cual permite considerar que dichos agentes tuvieron influencia en momentos previos y posteriores a su incorporación al suelo.

El material antracológico del sitio Los Tres Ombúes está representado por un conjunto de 100 carbones, 45 de los cuales proceden de la cuadrícula F2; y 55 de la cuadrícula F3. Sus dimensiones varían entre 6 y $24 \mathrm{~mm}$ de largo (promedio 9,2 $\mathrm{mm}$ ), y entre 3 y $11 \mathrm{~mm}$ de ancho (promedio 5,5 $\mathrm{mm}$ ). Por superar los $5 \mathrm{~mm}$ se trata de carbones de fracción grande (Chabal, 1982, en Piqué i Huerta, 1999), cuya identificación taxonómica es factible, puesto que suele serlo a partir de los 2-3 mm (Piqué i Huerta, 1999).

El análisis fue efectuado siguiendo los lineamientos planteados por Piqué i Huerta (1999, 2006), Pearsall (2000), Marconetto (2008) y Andreoni (2014). En principio se conformó una colección de referencia de muestras carbonizadas de las especies leñosas arbóreas que actualmente forman parte del entorno del sitio, para su comparación con los carbones arqueológicos. Se considera que 
la constitución de una colección de referencia carbonizada resulta útil para la identificación taxonómica de los restos antracológicos, dado que permite comparar directamente el carbón actual con las muestras arqueológicas (Marconetto, 2008) y observar características anatómicas, así como aqueIlas generadas por la combustión. En tal sentido, se empleó la carbonización experimental de muestras leñosas de las especies del talar Celtis tala, Jodina rhombifolia, Phytolacca dioica, Schinus longifolius y Scutia buxifolia; y aquellas de la costa rioplatense, Erythrina crista-galli y Salix humboldtiana. Si bien algunos arbustos pudieron emplearse como combustible, se consideró adecuado iniciar el estudio teniendo en cuenta las especies arbóreas. Se realizó la fractura manual de las muestras de la colección de referencia a fin de observar los caracteres anatómicos de las distintas maderas carbonizadas en los planos diagnósticos, evidenciados por los cortes transversal (CT), longitudinal tangencial (CLT) y longitudinal radial (CLR), al igual que la presencia de alteraciones producidas por el proceso de combustión. Estas muestras se observaron en un microscopio electrónico de barrido (MEB) Philips SEM 505. A partir de las imágenes obtenidas se describieron las características anatómicas de los tejidos leñosos de cada especie (porosidad, anillos de crecimiento, vasos, fibras, etc.) y eventuales rasgos de termoalteración. Cabe señalar que, aunque el proceso de carbonización modifica las características morfológicas cuantitativas, se conservan los rasgos cualitativos que permiten identificar las muestras carbonizadas (Solari, 2000).

Por último, las muestras arqueológicas se fracturaron de forma manual y se observaron en un microscopio óptico binocular Arcano XSZ107 BN, adaptado con luz incidente de fibra óptica (objetivos 10X y 40X), y luego se compararon con la colección de referencia para su identificación taxonómica. La observación de los tres planos permitió, en un alto porcentaje de casos, la identificación de la especie arbórea. Si bien en antracología se considera que los rasgos cualitativos permiten identificaciones a nivel de género, es posible, como señalan Marconetto y Gordillo (2008), considerar la afinidad de las muestras arqueológicas con las especies presentes en la región de estudio, que en este caso no presentan gran cercanía interespecífica.

Cabe destacar que la posibilidad de identificación de un carbón está condicionada en gran medida por el tamaño del fragmento, ya que mayores dimensiones facilitan su manipulación y la obtención de superficies más amplias para su observación. Sin embargo, el estado de conservación y las alteraciones presentes pueden dificultar el análisis de su estructura anatómica (Piqué i Huerta, 1999, 2006; Caruso Fermé, 2013; Andreoni, 2014). Algunos fragmentos no permitieron la observación de los caracteres anatómicos debido a su estado de preservación y las posibilidades de realizar el corte manual. Finalmente, es necesario señalar que las muestras de Erythrina crista-galli y Phytolacca dioica no fue posible observar con precisión el CLR, por lo cual su referencia es omitida en la descripción.

Simultáneamente se relevaron trabajos botánicos, arqueobotánicos y etnobotánicos referentes a las características y usos pasados y actuales de la madera de las especies de la colección de referencia (Tortorelli, 1956; Vervoorst, 1967; Biloni, 1990; Brunazzo, 1997; Lahitte et al., 1998; Demaio et al., 2002; Athor, 2006; Torres Robles y Tur, 2006; González y Frère, 2009; Brea et al., 2013, 2014; Pirondo y Keller, 2014; Aldazábal y Vásquez, 2015; Pochettino et al., 2016; Scarpa y Rosso, 2018; Doumecq, 2019). Considerando el alcance regional, se focalizó en el noreste bonaerense.

A continuación se detallan microscópicamente aquellas muestras que integran la colección de referencia de materiales carbonizados, a partir de la convención establecida por la International Association of Wood Anatomists (1989).

\section{Caracterización microscópica de las muestras que integran la colección de referencia}

Celtis tala (Figura 3 A-C)

CT: Anillos poco demarcados. Como señala Tortorelli (1956), presenta porosidad difusa. Poros de contorno circular a elíptico, solitarios, múltiples cortos (2-3) en disposición radial y, en menor proporción, múltiples largos (4-6). Parénquima axial paratraqueal, en bandas de más de 4 células de espesor, y parénquima apotraqueal confluente.

CLR: Radios heterocelulares formados por células procumbentes en el cuerpo y 2-3 hileras de células cuadrangulares en los márgenes.

CLT: Radios uniseriados y multiseriados de 2-3 células de ancho, presentan cristales de oxalato. Elementos de vaso cortos con tabiques rectos y placa de perforación simple. Punteaduras areoladas alternas. 
Erythrina crista-galli (Figura 3 D-E)

CT: Anillos no demarcados. Porosidad difusa. Poros de contorno circular mayormente solitarios, múltiples cortos (2-3) y, en menor proporción, múltiples largos (4 o más), con disposición radial. Parénquima paratraqueal y apotraqueal abundante, que forma bandas de 6-10 células. CLT: Parénquima axial estratificado. Vasos de trayectoria rectilínea, en punteaduras alternas areoladas y placa de perforación simple con tabique recto.

Jodina rhombifolia (Figura 3 F-H) CT: Anillos no demarcados. Porosidad difusa, poros dispuestos en patrón dendrítico diagonal a los radios, agrupados en racimos. Parénquima axial difuso y abundante, y paratraqueal escaso.

CLR: Radios heterocelulares formados por células procumbentes y una hilera marginal de células cuadrangulares.

CLT: Radios multiseriados de 2-4 células de ancho. Elementos de vaso con puntuaciones alternas de tabique recto a oblicuo.

Phytolacca dioica (Figura $3 \mathrm{I}-\mathrm{K}$ ) CT: Anillos de crecimiento demarcados. Porosidad semicircular. Poros con disposición radial, solitarios, múltiples cortos $y$, en menor proporción, múltiples largos. Parénquima paratraqueal y apotraqueal difuso-abundante. CLT: Elementos de vaso largos con punteaduras areoladas alternas, placas de perforación escalariforme y engrosamientos anulares. Leño con estratificación parcial del parénquima axial.
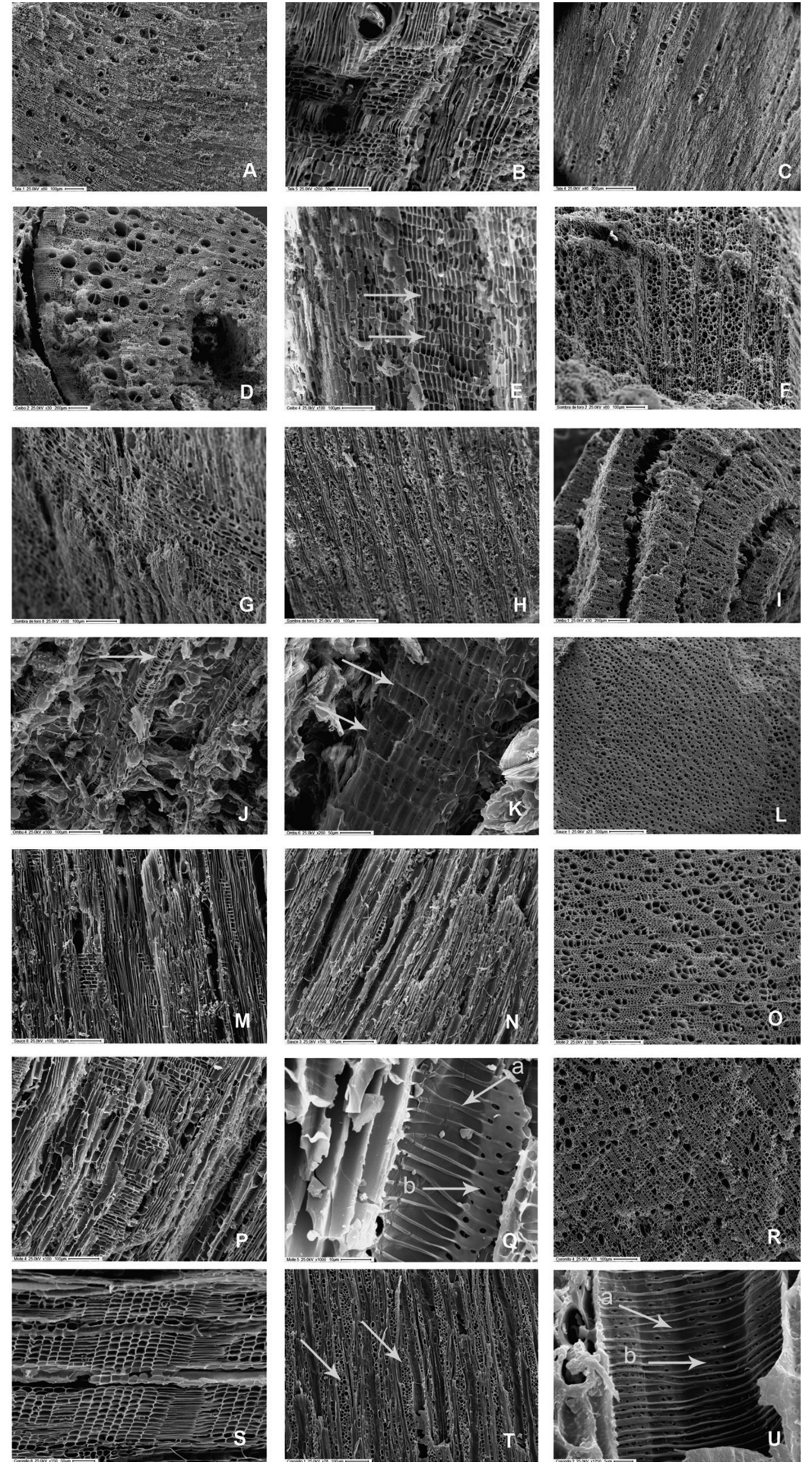

Figura 3. Imágenes obtenidas con microscopio electrónico de barrido (MEB) de las especies que integran la colección de referencia: A-C Celtis tala; A- sección transversal; B- sección longitudinal radial; C- sección longitudinal tangencial. D-E Erythrina crista-galli; D- sección transversal; E- sección longitudinal tangencial que muestra estratificación. F-H Jodina rhombifolia; F- sección transversal; G- sección longitudinal radial; $\mathrm{H}$ - sección longitudinal tangencial. I-K Phytolacca dioica; I- sección transversal; J- sección longitudinal tangencial que muestra vasos con engrosamientos anulares; K- sección longitudinal radial que muestra estratificación incompleta. L-N Salix humboldtiana; L- sección transversal; M- sección longitudinal radial; N- sección longitudinal tangencial. O-Q Schinus longifolius; O- sección transversal; P- sección longitudinal radial; Q- sección longitudinal tangencial que presenta pared interna de vaso con engrosamientos helicoidales (a) y punteaduras alternas (b). R-U Scutia buxifolia; R- sección transversal; S- sección longitudinal radial; T- sección longitudinal tangencial, que muestra radios y $\mathrm{U}$ - vasos con engrosamientos anulares (a) y punteaduras areoladas alternas (b). 
Salix humboldtiana (Figura $3 \mathrm{~L}-\mathrm{N}$ )

CT: Anillos demarcados por una banda de poros de mayor tamaño y fibras. Porosidad circular. Poros con disposición radial, solitarios, múltiples cortos y, en menor proporción, agrupados. Parénquima paratraqueal unilateral y apotraqueal difuso.

CLR: Radios homogéneos compuestos por células procumbentes. Vasos con placa de perforación oblicua.

CLT: Elementos de vaso largos con punteaduras alternas y placa de perforación simple.

Schinus longifolius (Figura $3 \mathrm{O}-\mathrm{Q}$ )

CT: Anillos demarcados. Porosidad difusa con tendencia a disposición dendrítica en patrones diagonales y radiales. Poros de contorno angular, solitarios, agrupados y racemiformes. Parénquima axial paratraqueal escaso, parénquima apotraqueal difuso y abundante. Radios de trayecto sinuoso.

CLR: Radios heterogéneos compuestos por células procumbentes y cúbicas. Vasos con engrosamientos anulares.

CLT: Radios uniseriados y multiseriados. Elementos de vaso cortos con engrosamientos helicoidales y punteaduras alternas. Placa de perforación simple y tabiques oblicuos. Presencia de canales radiales, como señala Tortorelli (1956).

\section{Scutia buxifolia (Figura 3 R-U)}

CT: Anillos no demarcados. Porosidad difusa. Poros solitarios, múltiples cortos (2-3) y múltiples largos (más de 4) en disposición radial. Radios de trayecto algo sinuoso. Abundantes fibras en disposición radial. Parénquima apotraqueal difuso. Presenta grietas de contracción radial producidas por la termoalteración.

CLR: Radios heterogéneos compuestos por células cuadradas, y células alargadas verticalmente en los márgenes. Vasos de trayectoria recta.

CLT: Vasos con placa de perforación oblicua, punteaduras areoladas alternas y engrosamientos anulares. Radios uniseriados y multiseriados. Elementos de vaso con engrosamientos anulares, placa de perforación simple y tabique recto a oblicuo.

\section{RESULTADOS}

A partir del análisis de los 100 carbones procedentes del sitio Los Tres Ombúes, se realizó la identificación taxonómica del 78\% de la muestra analizada. Se determinaron en total 78 fragmentos de carbón, mientras que 22 resultaron indeterminados. De estos últimos, siete fueron considerados indeterminables, ya que no fue posible observar rasgos anatómicos debido a su mal estado de conservación y/o la dificultad para realizar el corte manual. Se identificaron 31 carbones de Schinus longifolius, 25 de Celtis tala, nueve de Scutia buxifolia, seis de Salix humboldtiana, cuatro de Erythrina crista-galli y tres de Jodina rhombifolia (Tabla 1, Figura 4). Por lo tanto, se reconocieron elementos leñosos asignados a las especies arbóreas consideradas para el armado de la colección de referencia (Figura 5), incluyendo especies del talar y costeras, de diferentes calidades para su uso como leña, excepto Phytolacca dioica.

Ambas cuadrículas presentan frecuencias similares de determinación, aunque es levemente mayor en F2. Para dicha cuadrícula se observa el predominio de Schinus longifolius entre los carbones determinados, mientras que, para F3, Celtis tala es más frecuente. La especie de mayor abundancia actual en el entorno es Scutia buxifolia, menos representada en la submuestra de carbones determinados. Según trabajos etnobotánicos realizados en la zona,

\begin{tabular}{|l|c|c|c|}
\hline Especie & Cuadrícula F2 & Cuadrícula F3 & Total \\
\hline Celtis tala & 9 & 16 & 25 \\
\hline Erythrina crista-galli & 1 & 3 & 4 \\
\hline Jodina rhombifolia & 2 & 1 & 3 \\
\hline Salix humboldtiana & 2 & 4 & 6 \\
\hline Schinus longifolius & 21 & 10 & 31 \\
\hline Scutia buxifolia & 2 & 7 & 9 \\
\hline Subtotal determinados & 37 & 41 & 78 \\
\hline Subtotal indeterminados & 8 & 14 & 22 \\
\hline Total & 45 & 55 & 100 \\
\hline
\end{tabular}

Tabla 1. Conjunto antracológico del sitio Los Tres Ombúes. Identificaciones taxonómicas de los restos leñosos carbonizados.

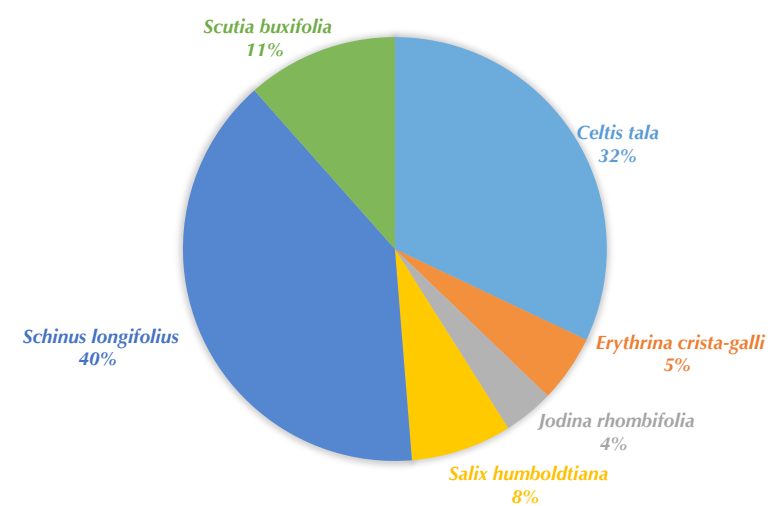

Figura 4. Conjunto antracológico del sitio Los Tres Ombúes. Gráfico de torta que señala los porcentajes de los taxones identificados en el sitio Los Tres Ombúes. 

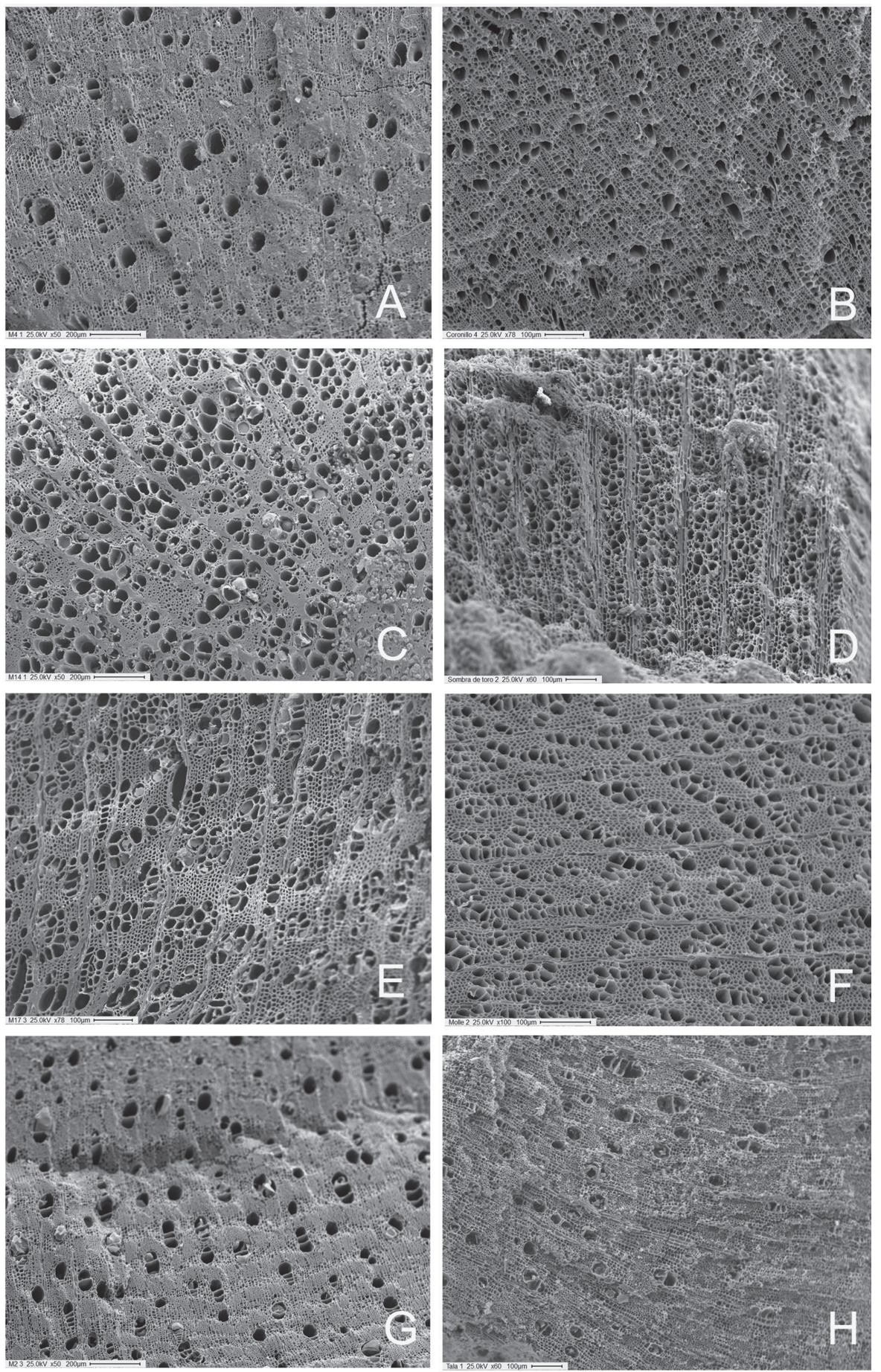

Figura 5. Imágenes obtenidas con microscopio electrónico de barrido (MEB) de muestras arqueológicas (izquierda) y muestras de referencia (derecha) en corte transversal, de las especies Scutia buxifolia (A-B), Jodina rhombifolia (C-D), Schinus longifolius (E-F) y Celtis tala $(\mathrm{G}-\mathrm{H})$.

C. tala y S. buxifolia son las especies más apreciadas como leña por los pobladores actuales, por producir abundante calor y buena brasa (Pochettino et al., 2016; Doumecq, 2019).

La baja frecuencia de Salix humboldtiana, Erythrina crista-galli y Jodina rhombifolia en el conjunto analizado no resulta llamativa, ya que se trata de maderas blandas, de baja calidad como combustible, aunque $S$. humboldtiana es valorada actualmente por generar buena Ilama (Doumecq, 2019). En cambio, Phytolacca dioica está ausente en el registro, en tanto su particular crecimiento anómalo, sin constituir leño verdadero, limita su empleo como combustible. Aunque este no fue registrado en el noreste bonaerense, se encontraron referencias etnobotánicas para Corrientes (Pirondo y Keller, 2014) y Chaco (Scarpa y Rosso, 2018). En la Tabla 2 se detallan, respecto de cada una de las especies arbóreas de la colección de referencia, su ubicación en el entorno del sitio, las características de la madera, usos citados en bibliografía y cantidad de carbones determinados taxonómicamente. Siempre que fue posible, los usos citados son referidos al noreste bonaerense y al PCS; en caso de no contar con dicha información, se consideraron empleos en otras regiones y de carácter general.

Finalmente, cabe destacar que en los fragmentos de carbón analizados no se observaron evidencias de alteraciones producidas por el proceso de combustión, tales como grietas de contracción radial o vitrificación. Sin embargo, en la muestra de referencia de Scutia buxifolia se visualizaron grietas de contracción radial. Esto implicaría la cocción a mayor temperatura en la muestra de referencia respecto de los carbones arqueológicos. 


\begin{tabular}{|c|c|c|c|c|c|}
\hline $\begin{array}{l}\text { Especie, autor y } \\
\text { familia }\end{array}$ & $\begin{array}{l}\text { Nombre } \\
\text { común }\end{array}$ & Ubicación & Características de la madera & Usos de la madera citados en bibliografía & $\begin{array}{c}\text { Carbones } \\
\text { determinados }\end{array}$ \\
\hline $\begin{array}{l}\text { Celtis tala Gillies } \\
\text { ex Planch, } \\
\text { Celtidaceae }\end{array}$ & Tala & Talar & $\begin{array}{l}\text { Madera dura y pesada. Peso } \\
\text { específico 0,8 } \mathrm{kg} / \mathrm{dm}^{3} \\
\text { (Tortorelli, 1956; Biloni, 1990; } \\
\text { Lahitte et al., 1998). }\end{array}$ & $\begin{array}{l}\text { En el noreste bonaerense, empleo prehispánico como } \\
\text { leña avalado por la identificación de carbones } \\
\text { (Brunazzo, 1997; González y Frère, 2009; Aldazábal y } \\
\text { Vázquez, 2015). Desde comienzos de la ocupación } \\
\text { hispánica bonaerense, uso intensivo como combustible } \\
\text { y en la construcción de viviendas y cercos (Vervoorst, } \\
\text { 1967; Athor, 2006; Torres Robles y Tur, 2006). Uso } \\
\text { actual como leña y carbón, y para fabricar mangos de } \\
\text { herramientas (Tortorelli, 1956; Biloni, 1990; Lahitte et } \\
\text { al., 1998). En el Parque costero del Sur (PCS) se registró } \\
\text { el empleo de leña, muy valorada por la larga duración } \\
\text { de sus brasas y el abundante calor generado (Pochettino } \\
\text { et al., 2016; Doumecq, 2019). }\end{array}$ & $N=25$ \\
\hline $\begin{array}{l}\text { Erythrina crista- } \\
\text { galli L., } \\
\text { Fabaceae }\end{array}$ & Ceibo & Costa & $\begin{array}{l}\text { Leño blando y liviano, poco } \\
\text { firme. Peso específico 0,26- } \\
0,29 \mathrm{~kg} / \mathrm{dm}^{3} \text { (Tortorelli, 1956). }\end{array}$ & $\begin{array}{l}\text { Utilizado para fabricar artefactos (Tortorelli, 1956; } \\
\text { Biloni, 1990; Lahitte et al., 1998). No se cita su empleo } \\
\text { como combustible. }\end{array}$ & $N=4$ \\
\hline $\begin{array}{l}\text { Jodina } \\
\text { rhombifolia } \\
\text { (Hook. \& Arn.) } \\
\text { Reissek., } \\
\text { Cervantesiaceae }\end{array}$ & $\begin{array}{l}\text { Sombra } \\
\text { de toro }\end{array}$ & Talar & $\begin{array}{l}\text { Madera blanda a semidura, } \\
\text { con peso específico de } 0,7 \mathrm{~kg} / \\
\mathrm{dm}^{3} \text { (Lahitte et al., 1998). }\end{array}$ & $\begin{array}{l}\text { Escasa utilización en construcciones rústicas y } \\
\text { fabricación de carretas (Biloni, 1990; Lahitte et al., } \\
\text { 1998). No se cita su empleo como combustible. }\end{array}$ & $N=3$ \\
\hline $\begin{array}{l}\text { Phytolacca } \\
\text { dioica L., } \\
\text { Phytolaccaceae }\end{array}$ & Ombú & Talar & $\begin{array}{llr}\text { Madera blanda } & \text { de escasa } \\
\text { consistencia, } & \text { por } r \text { la } \\
\text { alternancia de capas leñosas y } \\
\text { blandas. Bajo peso específico, } \\
0,3 \mathrm{~kg} / \mathrm{dm}^{3} \text { (Biloni, 1990). } \\
\end{array}$ & $\begin{array}{l}\text { Uso de leña en Corrientes (Pirondo y Keller, 2014) y } \\
\text { Chaco Húmedo (Scarpa y Rosso, 2018). }\end{array}$ & $N=0$ \\
\hline $\begin{array}{l}\text { Salix } \\
\text { humboldtiana } \\
\text { Wild., } \\
\text { Salicaceae }\end{array}$ & Sauce & Costa & 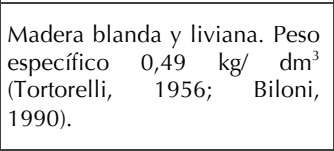 & $\begin{array}{l}\text { Se usa para fabricar celulosa, cajonería, tirantes, remos, } \\
\text { etc. (Lahitte et al., 1998) y proporciona abundante leña } \\
\text { (Tortorelli, 1956). En el PCS se registró el empleo de } \\
\text { leña, valorada por generar buena Ilama, aunque de } \\
\text { escasa duración (Doumecq, 2019). }\end{array}$ & $N=6$ \\
\hline $\begin{array}{l}\text { Schinus } \\
\text { longifolius } \\
\text { (Lindl.) Speg., } \\
\text { Anacardiaceae }\end{array}$ & Molle & Talar & $\begin{array}{l}\text { Sin referencias para la especie. } \\
\text { Dentro del mismo género, } \\
\text { Schinus molle, de madera } \\
\text { semidura y moderadamente } \\
\text { pesada, de unos } 0,7 \mathrm{~kg} / \mathrm{dm}^{3} \\
\text { (Tortorelli, 1956). }\end{array}$ & $\begin{array}{l}\text { En el PCS se registró el empleo de leña de Schinus } \\
\text { longifolius, calificada como buena (Doumecq, 2019). La } \\
\text { madera de otras especies del género (S. molle, S. ariera) } \\
\text { se emplea en carpintería y como combustible } \\
\text { (Tortorelli, 1956; Demaio et al., 2002). }\end{array}$ & $N=31$ \\
\hline $\begin{array}{l}\text { Scutia buxifolia } \\
\text { Reissek, } \\
\text { Rhamnaceae }\end{array}$ & Coronillo & Talar & $\begin{array}{l}\text { Madera dura y pesada, con un } \\
\text { peso específico cercano a } 1 \\
\mathrm{~kg} / \mathrm{dm}^{3} \text { (Lahitte et al., 1998). }\end{array}$ & $\begin{array}{l}\text { Se usa como leña y para fabricar postes (Biloni, 1990; } \\
\text { Lahitte et al., 1998). En el PCS la leña es empleada y } \\
\text { muy valorada por la duración de las brasas y el } \\
\text { abundante calor que genera (Pochettino et al., 2016; } \\
\text { Doumecq, 2019). }\end{array}$ & $N=9$ \\
\hline
\end{tabular}

Tabla 2. Conjunto antracológico del sitio Los Tres Ombúes. Detalle de las especies arbóreas de la colección de referencia, su ubicación en el entorno del sitio, las características de la madera, los usos citados en la bibliografía y la cantidad de carbones determinados taxonómicamente para cada especie.

\section{DISCUSIÓN Y CONSIDERACIONES FINALES}

Este trabajo constituye el primer análisis sistemático de carbones recuperados en un sitio arqueológico del noreste bonaerense, y contribuye a la arqueología regional al aportar una colección de referencia de leños actuales carbonizados factible de ser utilizada y ampliada en futuros trabajos. Cabe destacar que constituye un aporte significativo puesto que hasta el momento son pocos los estudios antracológicos en la región pampeana, quizá debido a que son escasos los carbones arqueológicos recuperados, en comparación con lo que sucede en otras regiones del país (Brea et al., 2014).

Los carbones identificados constituyen un alto porcentaje de la muestra $(78 \%)$ y se corresponden mayormente con las especies que conforman la colección de referencia, a excepción de Phytolacca dioica, que no fue identificada en el conjunto analizado. Las principales limitaciones para la identificación de carbones se vinculan con la alta fragmentación de las muestras y con el tamaño de cada una, relacionado con la posibilidad de corte manual para obtener una superficie observable al microscopio. En cuanto a la fragmentación de los carbones, es un proceso en el cual intervienen múltiples variables, tales como las propiedades anatómicas específicas, las condiciones de combustión y los procesos posdepositacionales, aspectos que imposibilitan la correlación entre el número de fragmentos y la biomasa quemada. Se considera la incidencia de dos variables fundamentales en la fragmentación de los carbones analizados; por un lado, los agentes que actuaron durante su enterramiento y su permanencia en el suelo, y por otro, las técnicas utilizadas para la recuperación del carbón vegetal durante la excavación.

Con respecto a las muestras indeterminadas, siete de ellas lo son debido a su mal estado de 
conservación y, en consecuencia, a la imposibilidad de su fractura manual. Las restantes podrían corresponder a especies diferentes de las que conforman la colección de referencia. Por ello, a futuro se considera la posibilidad de ampliar dicha colección incluyendo arbustos, subarbustos y enredaderas. Cabe señalar que en otros trabajos antracológicos fueron identificados carbones arqueológicos correspondientes con Cyperus giganteus, posiblemente Passiflora mburucuyá (Brea et al., 2013) y Baccharis salicifolia, especie arbustiva de alto poder calórico (Brea et al., 2014). Estas dos últimas especies también se encuentran en el entorno del sitio. Si bien no se relevó C. giganteus, hay numerosas ciperáceas en el área circundante. Brunazzo (1997) señala la presencia de restos de ciperáceas carbonizadas en el sitio La Higuera. Otra posibilidad es la representación de alguna especie arbórea que habitaba en la zona en el pasado y no actualmente, aunque la composición del talar era similar a la actual (Paez et al., 1999).

En el sitio Los Tres Ombúes no se identificaron estructuras de combustión, pero las marcas en fragmentos cerámicos y los huesos quemados recuperados evidencian el empleo del fuego para la cocción de piezas cerámicas y alimentos, como así también posibles acciones de descarte. Sumado a las referencias comentadas para otros sitios de la región, se puede considerar que en Los Tres Ombúes existieron estructuras de combustión que fueron fundamentales por brindar calor y protección, y para la realización de prácticas cotidianas como la preparación de comida y la manufactura cerámica. Además, es necesario considerar su importancia como lugar para reunirse y realizar otras prácticas necesarias para la reproducción social. Dichas estructuras habrían resultado alteradas por actividades de limpieza y el pisoteo de los habitantes del sitio. Luego, una vez abandonado este, habrían actuado distintos agentes posdepositacionales a lo largo del tiempo. De tal modo, los carbones se habrían fragmentado, dispersado y enterrado a partir de las tareas de acondicionamiento y limpieza, junto con la acción de agentes como el viento y el pisoteo.

Los resultados obtenidos evidencian la carbonización de maderas provenientes de especies arbóreas del talar y de la costa rioplatense. Asimismo, avalan la presencia de Celtis tala, Jodina rhombifolia, Schinus longifolius, Scutia buxifolia, Erythrina cristagalli y Salix humboldtiana en el pasado. El análisis de carbones dispersos -procedentes de distintos episodios de combustión ocurridos durante la ocupación del sitio- propone el uso de estas maderas como combustible por parte de sus habitantes.

Es esperable que los grupos cazadores-recolectores recolecten la madera empleada como combustible cerca de los campamentos. Esto varía en función de la disponibilidad y abundancia de especies en el entorno, de la funcionalidad, estacionalidad y duración de la ocupación del sitio y de la movilidad del grupo; es poco común el acopio en estas sociedades (Caruso Fermé, 2013). La disponibilidad y la facilidad de recolección habrían condicionado la obtención de la leña, pero también es necesario considerar otros aspectos intervinientes, ya que la selección y la utilización están mediadas por elecciones sociales (Piqué i Huerta, 1999, 2006). Por ejemplo, se consideran sus propiedades (poder calórico, humo, Ilama y duración de la brasa) y los objetivos de uso, que pueden ser variables. En consecuencia, los carbones domésticos constituyen residuos de maderas seleccionadas y empleadas por un grupo, de acuerdo con sus prácticas sociales, para realizar diferentes actividades. Por ello no es posible inferir condiciones paleoambientales a partir del registro antracológico, más allá de la presencia de las especies identificadas a partir del análisis.

En el conjunto analizado se identificaron carbones de Celtis tala y Scutia buxifolia, especies con maderas duras, de alto rendimiento como combustible. Por otro lado, la presencia de escasos carbones correspondientes a Salix humboldtiana, Schinus longifolius, Erythrina crista-galli y Jodina rhombifolia podría evidenciar el empleo complementario de leña de menor calidad. Estas especies habrían sido utilizadas especialmente para iniciar y/o avivar el fuego, o quizás se realizó su descarte en fogones, con posterioridad a su utilización con otros fines (e.g., fabricación de artefactos, uso medicinal). El conjunto de las especies identificadas permite proponer el uso complementario de especies arbóreas de leña dura y blanda en el manejo de los fogones, sin descartar el empleo de especies no arbóreas, como arbustos y enredaderas, en la alimentación del fuego. Además, algunos restos carbonizados podrían responder a causas distintas de su empleo como leña, como la combustión accidental y el empleo medicinal de las cenizas. Respecto de la ausencia de Phytolacca dioica en la muestra analizada, es posible considerar distintas explicaciones. Quizás las condiciones del suelo no permitieron la conservación de su madera, más blanda que otras por no constituir leño verdadero. Otra posibilidad 
es que esta especie no estuviera disponible en el entorno al momento de la ocupación del sitio. Una tercera explicación podría contemplar su valoración negativa como combustible u otros aspectos vinculados a un valor simbólico. Por ejemplo, Pirondo y Keller (2014) refieren a la consideración del ombú como una presencia singular en el paisaje, y a su valoración negativa, tanto en la región pampeana -donde se cree que causa desgracias a quienes habiten o se refugien bajo su sombra-, como en la región nordeste -donde se considera que es habitado por una presencia sobrenatural.

Se considera que las estrategias utilizadas para el manejo del fuego en el sitio Los Tres Ombúes se basaron en la utilización conjunta de varias especies con distintos atributos de combustión, y que las prácticas de recolección contemplaron la abundante disposición en el entorno mediada por las elecciones sociales. En tal sentido, para avanzar en el conocimiento de las prácticas de obtención y empleo de leña en el pasado, es necesario realizar nuevos estudios sistemáticos en la región, ampliar la excavación del sitio e implementar protocolos de recuperación para reducir la fragmentación del registro antracológico.

Finalmente, puede decirse que la leña constituyó un elemento de vital importancia para las prácticas cotidianas que los habitantes del sitio Los Tres Ombúes llevaron a cabo. La leña utilizada fue obtenida en la costa del Río de la Plata y principalmente en el talar, paisaje que estos grupos cazadoresrecolectores habitaron y significaron mediante sus prácticas, elecciones y decisiones en las que este entorno intervino activamente.

\section{Agradecimientos}

Este trabajo se enmarca en el proyecto UNLP 11/N882 "Investigaciones arqueológicas en los Partidos de Magdalena, Punta Indio y zona costera de Berisso, Provincia de Buenos Aires. Dinámicas y procesos sociales", y en el PICT 2015-1578 (FONCYT) "Los saberes botánicos locales ocultos en la pluri/interculturalidad: diversidad biocultural en las regiones rioplatense, nordeste y noroeste de la República Argentina".

Agradecemos a los evaluadores que aportaron a mejorar este trabajo, a nuestros compañeros del Laboratorio de Análisis Cerámico y especialmente a la Lic. Mariela Theiller, del Servicio de Microscopía

\section{del CINDECA (CONICET).}

\section{REFERENCIAS CITADAS}

Acuto, F. A. (2013). ¿Demasiados paisajes?: Múltiples teorías o múltiples subjetividades en la Arqueología del Paisaje. Anuario de Arqueología, 5, 31-50.

Aldazábal, V. y Vázquez, F. (2015). El registro arqueobotánico del sitio El Divisadero Monte 6 (Partido de General Lavalle, Buenos Aires). Revista de Antropología del Museo de Entre Ríos, 1(2), 83-90.

Aldazábal, V., Weiler, N. y Eugenio, E. (2004). Una perspectiva geoarqueológica para comprender la ocupación humana en la costa central de la provincia de Buenos Aires. Intersecciones en Antropología, 5, 29-38.

Andreoni, D. (2014). Plantas leñosas y estrategias humanas en el sur de Mendoza: una aproximación arqueobotánica [tesis doctoral, Universidad Nacional de La Plata]. Repositorio institucional UNLP: http:// sedici.unlp.edu.ar/handle/10915/36182

Arturi, M. (2006). Situación ambiental en la ecorregión espinal. En A. Brown, U. Martínez Ortiz, M. Acerbi y J. Corcuera (Eds.), La situación ambiental Argentina 2005 (pp. 241-246). Fundación Vida Silvestre Argentina.

Arturi, M. F. y Goya, J. F. (2004). Estructura, dinámica y manejo de los talares del NE de Buenos Aires. En M. F. Arturi, J. L. Frangi y J. F. Goya (Eds.), Ecología y manejo de los bosques de Argentina (pp. 1-24). Editorial de la Universidad Nacional de La Plata.

Athor, J. (2006). Referencias bibliográficas históricas que delatan la presencia del talar en la ciudad de Buenos Aires. En E. Mérida y J. Athor (Eds.), Talares bonaerenses y su conservación (pp. 218-222). Fundación de Historia Natural Félix de Azara.

Balesta, B., Paleo, M., Pérez Meroni, M. y Zagorodny, N. (1997). Revisión y estado actual de las investigaciones arqueológicas en el Parque Costero Sur (Pdo. Magdalena; Prov. de Buenos Aires). En M. A. Berón y G. G. Politis (Eds.), Arqueología pampeana en la década de los '90 (pp. 147-160). Museo de Historia Natural de San Rafael.

Biloni, J. S. (1990). Árboles autóctonos argentinos. Tipográfica Editora Argentina.

Brea, M., Franco, M. J., Bonomo, M. y Politis, G. (2013). Análisis antracológico preliminar del sitio arqueológico Los Tres Cerros 1 (Delta Superior del río Paraná), provincia de Entre Ríos. Revista del Museo de La Plata, Sección Antropología, 13(87), 346-360.

Brea, M., Mazzanti, D. y Martínez, G. A. (2014). Selección y uso de los recursos madereros en cazadores-recolectores de la transición Pleistoceno-Holoceno y Holoceno medio, sierras de Tandilia oriental, Argentina. Revista del 
Museo Argentino de Ciencias Naturales, 16(2), 129-141.

Brunazzo, G. A. (1997). Ocupación prehispánica en el litoral platense meridional: el sitio La Higuera (Pdo. de Berisso, provincia de Buenos Aires). Resúmenes Jornadas de Comunicaciones Científicas 1996/97 de la Facultad de Ciencias Naturales y Museo (UNLP) (p. 100).

Brunazzo, G. A. (1999). Investigaciones arqueológicas en el sitio La Norma (Partido de Berisso, Provincia de Buenos Aires, Argentina). Actas del XII Congreso Nacional de Arqueología Argentina, 3 (pp. 101-106).

Caruso Fermé, L. (2013). Los recursos vegetales en arqueología. Estrategias de muestreo y estudio del material leñoso. Dunken.

Demaio, P., Ola Karlin, U. y Medina, M. (2002). Árboles nativos del centro de Argentina. L.O.L.A.

Doumecq, M. B. (2019). Evaluación etnobotánica de los recursos vegetales combustibles actuales y potenciales de la ribera platense (provincia de Buenos Aires, Argentina) [tesis doctoral inédita, Universidad Nacional de La Plata].

Ghiani Echenique, N. y Paleo, M. C. (2018). Los Tres Ombúes, un sitio arqueológico de cazadoresrecolectores en Punta Piedras (partido de Punta Indio, provincia de Buenos Aires). Revista de Antropología del Museo de Entre Ríos, 4(1), 68-86.

González, M. I. (2005). Arqueología de alfareros-cazadores y pescadores pampeanos. Sociedad Argentina de Antropología.

González, M. I. y Frère, M. M. (2009). Talares y paisaje fluvial bonaerense: arqueología del río Salado. Intersecciones en Antropología, 10, 249-265.

Ingold, T. (1993). The temporality of the Landscape. World Archaeology, 25(2), 152-174.

International Association of Wood Anatomists (IAWA) (1989). List of microscopic features for hardwood identification. IAWA Bulletin, 10, 219-332.

Lahitte H., Hurrell, J., Belgrano, M. y Jankowski, L. (1998). Árboles Rioplatenses. L.O.L.A.

Marconetto, M. B. (2008). Recursos forestales y el proceso de diferenciación social en tiempos prehispánicos en el valle de Ambato, Catamarca. South American Achaeology Series 3. British Archaeological Reports.

Marconetto, M. B. y I. Gordillo (2008). "Los techos del vecino": Análisis antracológico de restos de construcción carbonizados de los sitios "Iglesia de los indios" y "Piedras blancas" (Catamarca). Darwiniana, 46(2), 213-226
Orejas, A. (1991). Arqueología del paisaje: historia, problemas y perspectivas. Archivo Español de Arqueología, 64(163/164), 191-230.

Paez, M. M., Paleo, M. C., Pérez Meroni, M. y Pastorino, S. (1999). El bosque de tala como recurso potencial: interpretación arqueológica y palinológica. Resúmenes del XIII Congreso Nacional de Arqueología Argentina (pp. 369-370).

Paleo, M. C. y Pérez Meroni, M. (2004). Problemáticas vinculadas a las estrategias de subsistencia de la Localidad Arqueológica Barrio San Clemente. En C. Gradin y F. Oliva (Eds.), La Región Pampeana. Su pasado arqueológico (pp. 311-320). Universidad Nacional de Rosario; Laborde editor.

Paleo, M. C. y Pérez Meroni, M. (2007). Primeros resultados del sitio "Las Marías", Partido de Magdalena. Provincia de Buenos Aires. En F. Oliva, N. de Grandis y J. Rodríguez (Comps.), Arqueología Argentina en los inicios de un nuevo siglo I (pp. 275-286). Laborde editor.

Paleo, M. C., Paez, M. M. y Pérez Meroni, M. (2002). Condiciones ambientales y ocupación humana durante el Holoceno tardío en el litoral fluvial bonaerense. En D. Mazzanti, M. Berón y F. Oliva (Eds.), Del mar a los salitrales: diez mil años de historia pampeana en el umbral del tercer milenio (pp. 365-376). Universidad Nacional de Mar del Plata.

Parodi, L. R. (1940). Distribución geográfica de los talares de la Provincia de Buenos Aires. Darwiniana, 4, 33-56.

Pearsall, D. M. (2000) Paleoethnobotany. A handbook of procedures. Academic Press.

Pérez Meroni, M., Paleo, M. C., Pochettino, M. L. y Lema, V. S. (2010) Procesamiento y consumo de vegetales por grupos cazadores-recolectores del Holoceno tardío, en los partidos de Magdalena y Punta Indio, provincia de Buenos Aires. En M. Berón, L. Luna, M. Bonomo, C. Montalvo, C. Aranda y M. Carrera Aizpitarte (Eds.), Mamül Mapu: Pasado y presente desde la arqueología pampeana (pp. 215-226). Ediciones del Espinillo.

Piqué i Huerta, R. (1999). Producción y uso de combustible vegetal arqueológico: Una evaluación arqueológica (Treballs d’Etnoarqueología 3). Universidad Autónoma de Barcelona.

Piqué i Huerta, R. (2006). Los carbones y las maderas de contextos arqueológicos y el paleoambiente. Ecosistemas, 15, 31-38.

Pirondo, A. y Keller, H. A. (2014) El "ombú" (Phytolacca dioica: Phytolaccaceae) en la vida del hombre de Iberá (Corrientes, Argentina). Estudio de caso sobre su interrelación. Etnobiología, 12(3), 68-75. 
Pochettino, M. L., Paleo, M. C., Ghiani Echenique, N., Doumecq, M. B. y Hurrell, J. A. (2016). La construcción del paisaje del litoral rioplatense 1. Las plantas y sus usos como patrimonio del Parque Costero del Sur. Editorial Universitaria de La Plata.

Scarpa, G. F. y Rosso, C. N. (2018). Etnobotánica histórica de grupos criollos de Argentina III: Identificación taxonómica y análisis de datos no-medicinales del Chaco Húmedo provenientes de la Encuesta Nacional de Folklore de 1921. Bonplandia, 27(1), 31-57.

Sempé, C., Balesta, B., Paleo, M. C., Pérez Meroni, M. y Zagorodny, N. (1991). Arqueología del Parque Costero del Sur. Magdalena, Pcia. de Buenos Aires. Boletín del Centro, 3, 116-124.
Solari, M. E. (2000). Antracología, modo de empleo: En torno a paisajes, maderas y fogones. Revista Austral de Ciencias Sociales, 4, 167-174.

Torres Robles, S. S. y Tur, N. M. (2006). Los talares de la provincia de Buenos Aires. En A. Brown, U. Martínez Ortiz, M. Acerbi y J. Corcuera (Eds.), La situación ambiental Argentina 2005 (pp. 246-250). Fundación Vida Silvestre Argentina.

Tortorelli, L. A. (1956). Maderas y bosques argentinos. ACME.

Vervoorst, F. (1967). Las comunidades de la Depresión del Salado, provincia de Buenos Aires (Serie Fitogeográfica 7). SEAGN-Instituto Nacional de Tecnología Agropecuaria (INTA). 